\title{
A COMPARISON OF HUMIC FRACTIONS OF CHERNOZEMIC AND LUVISOLIC SOILS BY ELEMENTAL ANALYSES, UV AND ESR SPECTROSCOPY
}

\author{
D. W. ANDERSON, D. B. RUSSELL, R. J. ST. ARNAUD, and E. A. PAUL \\ Saskatchewan Institute of Pedology and the Department of Chemistry and Chemical \\ Engineering, University of Saskatchewan, Saskatoon, Sask. S7N 0W0. Joint \\ contribution no. R138, received 9 April 1974, accepted 27 Aug. 1974.
}

\begin{abstract}
Anderson, D. W., Russell, D. B., St. Arnaud, R. J. and Paul, E. A. 1974. A comparison of humic fractions of Chernozemic and Luvisolic soils by elemental analyses, UV and ESR spectroscopy. Can. J. Soil Sci. 54: 447-456.
\end{abstract}

\begin{abstract}
The Ah horizons of a Brown-Dark Brown-Black-Dark Gray-Gray Luvisolic sequence of Canadian grassland and forest soils were studied. Clay-associated humus was present in greater proportions in the grassland than in forest soils, particularly in the grassland soils of the more arid regions. Amounts of alkalipyrophosphate-extractable humus increased in the Brown to Gray Luvisolic sequence. Alkali-pyrophosphate-extractable humic acid (HA-A) contents were greatest in the Black and Dark Gray soils. $\mathrm{C}: \mathrm{H}$ ratios, extinction coefficients at $280 \mathrm{~nm}\left(\mathrm{E}_{2 \times 0}\right)$, and resistance to acid hydrolysis of the HA-A and clay-associated HA-B increased in the Brown to Gray Luvisolic sequence. Free radical concentrations were least for the Brown and Dark Brown soils, moderate for the Black and greatest for the Gray Luvisolic soils. The data suggest an increase in the proportion of aromatic components in the humic acids in going from the Brown to the Gray Luvisolic soils. An objective, multivariate similarity analysis based on 22 humus characteristics showed a relationship between soil zone or soil environment and the nature of the soil's humus.
\end{abstract}

Les auteurs ont étudié les horizons Ah d'une séquence de sols Bruns-Brun foncéNoirs-Gris foncé-Gris luvisoliques dans les sols de prairie et de forêt canadiens. On a trouvé de plus fortes proportions d'humus associé à l'argile dans les sols de prairie que dans les sols forestiers, plus particulièrement dans les régions plus arides. Les teneurs en humus extractible au pyrophosphate de $\mathrm{Na}$ ont augmenté tout au long de la séquence. Les teneurs en acide humique extractible au pyrophosphate (HA-A) ont atteint leurs valeurs maximums dans les sols Noirs et Gris foncé. Le rapport $\mathrm{C} / \mathrm{H}$, le coefficient d'extinction à $280 \mathrm{~nm}\left(\mathrm{E}_{\mathrm{x}+0}\right)$ et la résistance à l'hydrolyse acide des HA-A et des HA-B associés à l'argile ont tous augmenté tout au long de la séquence. Les concentrations en radicaux libres étaient les plus basses dans les sols Bruns et Brun foncé, moyennes dans les Noirs et le plus hautes dans les Gris luvisoliques. Les données révèlent un accroissement de la proportion des composants aromatiques des acides humiques à partir des sols Bruns aux Gris luvisoliques. Une analyse objective de similarité à plusieurs variables basée sur 22 caractéristiques de l'humus a fait ressortir une relation entre la nature de l'humus et la zone de sol ou son environment (prairie ou forêt).

The content and characteristics of the organic matter in a soil are the products of the interaction of many biotic, physical and chemical soil environmental factors over time. Characterization of soil humus not only adds to our basic knowledge of the soil, but, when several related soils are considered, may enhance our general knowledge of humus formation and transformations in soil. Broad soil zones, products of regular

Can. J. Soil Sci. 54: 447-456 (Nov, 1974) changes in climate and vegetation, and a general uniformity of glacial till parent materials make Saskatchewan an excellent region for studying soil components such as humus over an environmental gradient. A recently developed extraction-fractionation technique (Anderson et al. 1974) appeared suitable for a study of the organic matter of a zonal sequence of soils.

Due to the heterogeneity of soil humus and the complexity of its interactions with 


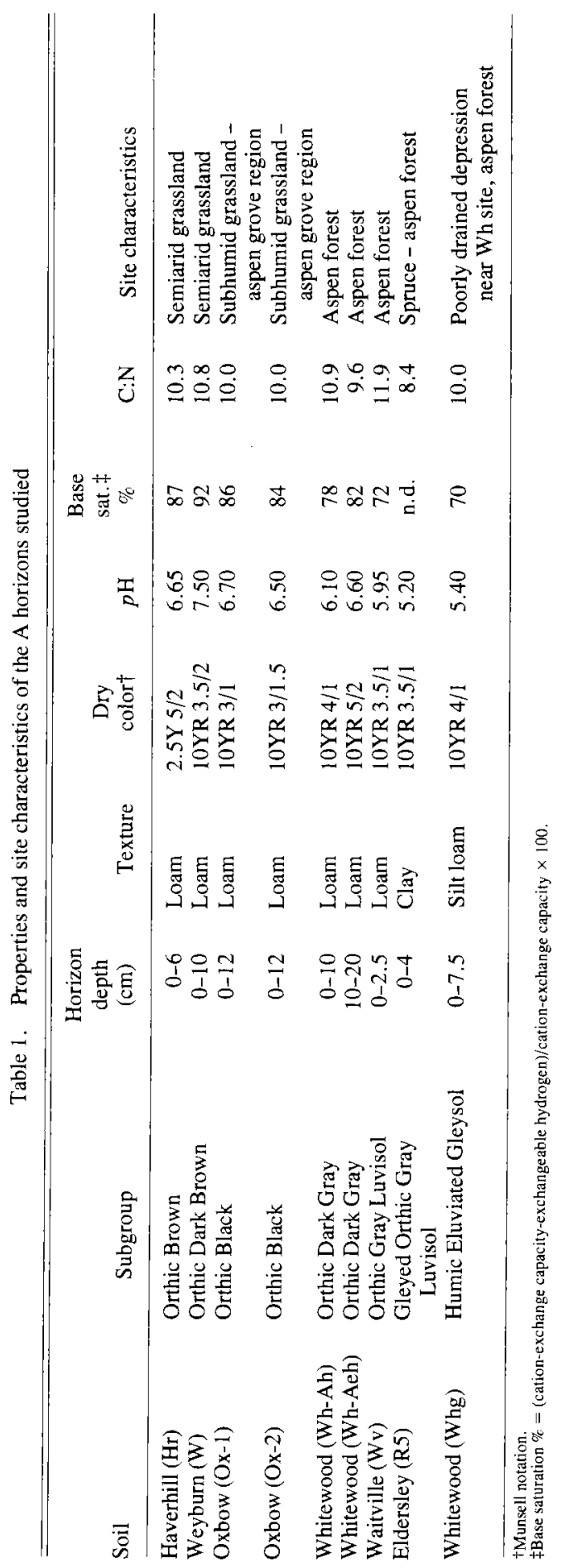


the soil environment it was decided that several humus properties be considered so that trends and general relationships noted for individual humus properties could reinforce each other and yield a comprehensive theory applicable to the entire system. Multivariate statistical techniques that allow an assessment of the level of similarity between units based on a large number of properties were used (Norris 1970).

\section{MATERIALS AND METHODS}

\section{Soils and Their Environment}

The soils were selected to include a range from the Brown soils of the semiarid grassland, through moist grassland and transitional types, to the Gray Luvisolic soils of subhumid forested regions (Table 1). Annual precipitation increases from 30 to $35 \mathrm{~cm}$ in the Brown soil zone, to $33-38 \mathrm{~cm}$ in the Dark Brown and to $36-45 \mathrm{~cm}$ in the Black and Gray Luvisolic zones (Mitchell et al. 1944). Growing season moisture deficits are considerably greater in the warmer Brown and Dark Brown zones than in the Black and Gray Luvisolic zones, and droughts are more frequent. Degree days above 5.0 $\mathrm{C}$ range from 1,440 in the Brown and Dark Brown, to 1,330 in the Black and 1,220 or less in the Gray Luvisolic regions. Mean annual soil temperatures $(20 \mathrm{~cm}$ depth) are about $4-5 \mathrm{C}$, mean growing season soil temperatures about $15-18 \mathrm{C}$, and the soils are frozen in winter (Baier and Russelo 1970). The climate of this region is more similar to that of the West $\mathrm{Si}$ berian Chernozem zone than it is to the climate of the Chernozem zones of Europe (Ivanova et al. 1962).

The A horizons of virgin soils were studied. All except the Gray Luvisolic R5 soil have developed on medium-textured glacial till that contains $15-20 \%$ lime carbonates; the R5 soil was formed on a calcareous clay lacustrine deposit. Chemical and morphological properties of the soils are given in Table 1. The Brown (Hr) and Dark Brown, Weyburn (W) Ah horizons contained relatively large amounts of partially decomposed roots. Considerably fewer roots were observed in the Ah horizons of the Black and Dark Gray soils. The Gray Luvisolic Ah horizons contain substantial amounts of charcoal and woody fragments.

\section{Lahoratory Methods}

The extraction-fractionation method used (Anderson et al. 1974) includes a principal extraction with $0.1 \mathrm{~N} \mathrm{NaOH}-0.1 \mathrm{M} \mathrm{Na} \mathrm{Na}_{2} \mathrm{O}_{7}$. $1 \mathrm{OH}, \mathrm{O}$ mixture. This extract was termed C-ext$A$ and was fractionated into humic acid (HA-A) and fulvic acid (FA-A). A second fraction, thought to be clay-associated, was isolated following ultrasonic dispersion in water of the residue from the first extraction. This fraction was separated as the supernatant following high-speed centrifugation $(10,400 \mathrm{~g})$ and was termed C-ext-B. The bulk of the C-ext-B precipitated at $p \mathrm{H} 1.5$ and is termed HA-B.

Organic carbon in the soils and extracts was measured by dichromate oxidation with external heating (Mebius 1960). Carbon and $\mathrm{H}$ analyses of the humic materials were made by Mikrolabor, Bonn, West Germany, using dry combustion techniques. Nitrogen was determined by the semimicro Kjeldahl technique (Bremner 1965). The acid hydrolysis treatments involved boiling humic acids in $6 \mathrm{~N} \mathrm{HCl}$ under reflux for $16-18 \mathrm{~h}$.

Extinction coefficients in the ultraviolet-visible region were measured on Na-humate solutions containing $17 \mathrm{ppm}$ humate-C, buffered to $p \mathrm{H} 7$ in $0.05 \mathrm{M} \mathrm{NaHCO}_{3}$. Extinction coefficients at 465 and $665 \mathrm{~nm}$, used in calculating $\mathrm{E}_{4}: \mathrm{E}_{8}$ ratios, were measured on similar solutions containing $34 \mathrm{ppm}$ C. A Beckman DBG spectrophotometer and a $1-\mathrm{cm}$ cell were used.

Electron spin resonance (ESR) measurements were made on low-ash (0-2\%), finely ground humic acid samples that had been dried over a desiccant. Sufficient sample $(15-30 \mathrm{mg})$ to fill the standard fused quartz ESR tube to a height of 3-4 mm was transferred to the tube, and the tube stoppered. The samples were transferred by placing a little of the sample into the end of a thin-walled metal tube whose outer diameter was fractionally less than that of the inner diameter of the quartz tube and transferring the sample to the bottom of the ESR tube, taking care that none of the sample adhered to the walls. The weight of each sample in the tube was determined by weighing first the empty tube and then the tube plus sample. All weighings were made on a Mettler microbalance, with an accuracy of $\pm 2 \mu \mathrm{g}$. ESR spectra were recorded at room temperature on a Varian V-4502 spectrometer with a $9.3 \mathrm{GHz}$ nominal operating frequency equipped with a Mark II Fieldail and employing both $100 \mathrm{KHz}$ and $400 \mathrm{~Hz}$ modulation. A Varian V-4537 $\left(\mathrm{TE}_{10+4}\right)$ double cavity was used in the measurement of spin concentrations. Spectra were recorded on an XYZ two-pen Hewlett-Packard recorder. The magnetic field at the sample was found by adding a microscopic crystal of DPPH (diphenylpicrylhydrazyl) to the sample after the measurement of spin concentrations had been made, and re-recording the spectrum; this eliminates any distortion of the field due to the presence of the quartz sample tube. The 
field sweep was calibrated against a dilute solution of Fremy's salt (potassium nitrosodisulphonate).

Spin concentrations were found by comparison with a standard carbon sample (prepared and standardized by D.E.G. Austen in 1958 and re-standardized in a large number of U.K. and European laboratories in the period 196170 ) containing $17.4 \times 10^{15}$ spins $/ g$ and having a peak-peak line-width of 5.0 gauss. The carbon sample was prepared for ESR use in the same way as the humic acid samples. The carbon sample and a humic acid sample were placed in each of the two halves of the double cavity, care being taken in each case to ensure that each sample was placed in the geometric center of its half of the cavity. Spectra were then recorded simultaneously using $100 \mathrm{KHz}$ modulation for the humic acid sample and $400 \mathrm{~Hz}$ modulation for the carbon standard. Spectra were then re-recorded simultaneously using 400 $\mathrm{Hz}$ modulation for the humic acid sample and $100 \mathrm{KHz}$ modulation for the carbon standard. The positions of the sample and standard were then reversed and the procedure repeated. The weight of carbon used $(1.18 \mathrm{mg})$ was so chosen that the number of spins was approximately the same as that found in the humic acid samples. In addition, at both $100 \mathrm{KHz}$ and $400 \mathrm{~Hz}$, the modulation amplititudes were kept constant throughout the entire series of experiments, spectra of suitable size being obtained by altering the gain settings. Experimental measurements of spectrum size for different gain settings showed that the settings were linear within $2 \%$ over the range used. The number of spins in each sample was found by double integration of the spectra and comparison of the standard and sample spectra obtained at (a) $100 \mathrm{KHz}$ and (b) $400 \mathrm{~Hz}$.

\section{RESULTS \\ Organic Matter Content and Composition}

The relatively thick Ah horizons of the Dark Brown (W), Black (Ox-1 and Ox-2), and Dark Gray $(W h)$ soils contained the largest total amounts of organic $\mathrm{C}$ or humus (Table 2). However, percentages of organic $C$ were higher in the much thinner, forest Ah horizons. The amount of organic $\mathrm{C}$ soluble in alkali-pyrophosphate (C-ext-A) was $26-27 \%$ in the semiarid grassland $\mathrm{Hr}$ and $\mathrm{W}$ Ah horizons, $38-39 \%$ in the Black Ox-1 and $\mathrm{Ox}-2$, and $44-48 \%$ in the Dark Gray and Gray Luvisolic Ah horizons. Conversely, the data demonstrate a gradual increase in humin content (alkali-pyrophosphate insoluble material) in the reverse sequence. HA-A contents and humic:fulvic acid ratios were least in the Brown $(\mathrm{Hr})$ and generally increased along the Brown-Gray Luvisolic sequence. In absolute terms, humic acid contents are greatest in the Black Ah horizons $(\mathrm{Ox}-1, \mathrm{Ox}-2)$. The C-ext-B fraction accounted for about $20 \%$ of the organic C, except for the Wv Ah horizon, which contained $11 \%$. Generally, the ratios C-ext-A: C-ext-B increased in the Brown to Gray Luvisolic sequence, corresponding to larger contents of C-ext-A and HA-A in the Black, Dark Gray and Gray Luvisolic soils and suggesting a decrease in the relative importance of clay-associated humus in the forest Ah horizons. This is in agreement with thinsection observations (St. Arnaud and White-

Table 2. Fractional composition of the humus

\begin{tabular}{|c|c|c|c|c|c|c|c|}
\hline \multirow[b]{3}{*}{ Soil } & \multirow{3}{*}{$\begin{array}{l}\text { Total } \\
\text { soil } \\
\text { organic C } \\
(\%)\end{array}$} & \multicolumn{6}{|c|}{ Fractional composition, as \% of total organic $\mathrm{C}$} \\
\hline & & \multirow{2}{*}{$\begin{array}{c}\text { C-ext-A } \\
(\%)\end{array}$} & \multirow{2}{*}{$\begin{array}{c}\mathrm{C}_{\mathrm{HA}-\mathrm{A}} \\
(\%)\end{array}$} & \multirow{2}{*}{$\begin{array}{c}\mathrm{C}_{\mathrm{FA}-\mathrm{A}} \\
(\%)\end{array}$} & \multirow{2}{*}{$\frac{\mathrm{C}_{\mathrm{HA}-\mathrm{A}}}{\mathrm{C}_{\mathrm{FA}-\mathrm{A}}}$} & \multirow{2}{*}{$\begin{array}{c}\text { C-ext-B } \\
(\%)\end{array}$} & C-ext-A \\
\hline & & & & & & & C-ext-B \\
\hline $\mathrm{Hr}$ & 3.71 & 26.4 & 11.6 & 14.8 & 0.8 & 19.2 & 1.4 \\
\hline W & 4.75 & 27.5 & 14.1 & 13.4 & 1.1 & 19.7 & 1.4 \\
\hline Ox-1 & 3.62 & 39.4 & 20.9 & 18.4 & 1.1 & 24.6 & 1.6 \\
\hline Ox-2 & 5.35 & 38.3 & 24.8 & 13.5 & 1.8 & 21.5 & 1.8 \\
\hline Wh-Ah & 4.25 & 47.6 & 30.4 & 17.2 & 1.6 & 18.2 & 2.6 \\
\hline Wh-Aeh & 1.34 & 46.2 & 28.4 & 17.8 & 1.4 & 24.8 & 1.9 \\
\hline Wv & 9.51 & 44.9 & 31.8 & 13.1 & 2.4 & 11.0 & 4.1 \\
\hline R5 & 5.60 & 43.8 & 25.8 & 17.9 & 1.4 & 21.4 & 2.1 \\
\hline Whg & 6.00 & 49.8 & 31.8 & 18.0 & 1.8 & 15.2 & 3.3 \\
\hline
\end{tabular}


side 1963), which revealed that humus and humus-clay complexes dominate the fabric of Chernozemic Ah horizons and are less significant in Luvisolic Ah horizons.

The content and factional composition of the humus of the poorly drained Whg Ah was similar to the adjacent Wh-Ah.

\section{Chemical Properties}

The C content of the HA-A on an ash-free basis ranged from a low of $52.6 \%$ for the Brown $\mathrm{Hr}$ Ah horizon to $55.2 \%$ for the Gray Luvisolic R5 Ah (Table 3). Consistent differences related to soil type were not observed. The $\mathrm{C}$ content of the HA-B was generally $1-2 \%$ less than the corresponding HA-A. Similarly, the $\mathbf{H}$ content of the HA-A ranged from $4.85 \%$ for the $\mathrm{Hr}$ Ah to values of $3.5-4.2 \%$ for the Dark Gray (Wh-Ah, Wh-Aeh) and Gray Luvisolic (R5) Ah horizons, with no consistent changes related to soil type. The $\mathbf{H}$ content of the HA-B was considerably greater than the HA-A, resulting in lower $\mathrm{C}: \mathrm{H}$ ratios for the HA-B. Decreases in the $\mathrm{H}$ content, coupled with slight increases in the $\mathrm{C}$ content of the humic acids result in general, but irregular, increases in the $\mathrm{C}: \mathrm{H}$ ratios in the Brown to Gray Luvisolic sequence. $\mathrm{C}: \mathrm{H}$ ratios have been used as indices of aromatic condensation (Kononova and Alexandrova 1973), widening with increase in condensation.

The $\mathbf{N}$ content of the HA-B is greater than that of the HA-A, resulting in narrower $C: N$ ratios for the HA-B. The C:N ratios of the HA-A are about 12 or 13 , except for the $R 5$ sample which has a ratio of 10 . The $\mathrm{C}: \mathrm{N}$ ratios of the HA-B are in the range of 10 11 , except for $\mathrm{R} 5$ with a ratio of 8.7 .

Amounts of HA-A carbon hydrolyzable in $6 \mathrm{~N} \mathrm{HCl}$ varied from $38 \%$ for the $\mathrm{Hr}$ Ah horizon to values of $33 \%$ or less for Wh, Wv and R5. The HA-B is more susceptible to acid hydrolysis, but shows the same trend as the HA-A over the range of soils studied. The proportion of humic acid nitrogen hydrolyzable ranged from 75 to $48 \%$ for the HA-A and 89 to $58 \%$ for the HA-B. In comparing soils, values for both the HA-A and HA-B were greatest for the Brown $\mathrm{Hr}$ Ah horizon, lowest for the Gray Luvisolic R5 Ah.

The ESR spectra of the humic acid samples consisted of a single line devoid of any hyperfine splitting (Fig. 1). For most samples, the line-shape was approximately Lorentzian (Table 4). It was observed that: (a) the greater the line-width, the greater the

Table 3. Chemical properties of the HA-A and HA-B fractions

\begin{tabular}{|c|c|c|c|c|c|c|c|c|}
\hline Soil & Frac. & $\begin{array}{c}\mathrm{C} \\
(\%)\end{array}$ & $\begin{array}{c}\mathbf{H} \\
(\%)\end{array}$ & $\frac{N}{\%}$ & $\begin{array}{c}\mathrm{C}: \mathrm{H} \\
\text { (atomic) }\end{array}$ & $\mathrm{C}: \mathrm{N}$ & $\begin{array}{c}\text { C hyd. } \\
(\%)\end{array}$ & $\begin{array}{c}\text { N hyd. } \\
(\%)\end{array}$ \\
\hline $\mathrm{Hr}$ & $\begin{array}{l}\text { HA-A } \\
\text { HA-B }\end{array}$ & $\begin{array}{l}52.6 \\
53.5\end{array}$ & $\begin{array}{l}4.85 \\
6.97\end{array}$ & $\begin{array}{l}3.84 \\
5.06\end{array}$ & $\begin{array}{l}0.92 \\
0.65\end{array}$ & $\begin{array}{l}13.2 \\
10.6\end{array}$ & $\begin{array}{l}38 \\
52\end{array}$ & $\begin{array}{l}75 \\
89\end{array}$ \\
\hline W & $\begin{array}{l}\text { HA-A } \\
\text { HA-B }\end{array}$ & $\begin{array}{l}54.7 \\
53.1\end{array}$ & $\begin{array}{l}4.43 \\
6.17\end{array}$ & $\begin{array}{l}4.05 \\
4.66\end{array}$ & $\begin{array}{l}1.03 \\
0.72\end{array}$ & $\begin{array}{l}13.5 \\
11.4\end{array}$ & $\begin{array}{l}35 \\
52\end{array}$ & $\begin{array}{l}66 \\
87\end{array}$ \\
\hline Ox-1 & $\begin{array}{l}\text { HA-A } \\
\text { HA-B }\end{array}$ & $\begin{array}{l}54.3 \\
50.9\end{array}$ & $\begin{array}{l}4.12 \\
5.79\end{array}$ & $\begin{array}{l}4.01 \\
5.21\end{array}$ & $\begin{array}{l}1.16 \\
0.78\end{array}$ & $\begin{array}{r}13.4 \\
9.9\end{array}$ & $\begin{array}{l}34 \\
53\end{array}$ & $\begin{array}{l}61 \\
85\end{array}$ \\
\hline$O x-2$ & $\begin{array}{l}\text { HA-A } \\
\text { HA-B }\end{array}$ & $\begin{array}{c}53.9 \\
-\dagger\end{array}$ & $\begin{array}{c}4.26 \\
-\end{array}$ & $\begin{array}{c}4.10 \\
-\end{array}$ & $\begin{array}{c}1.07 \\
-\end{array}$ & $\begin{array}{c}13.1 \\
-\end{array}$ & $\begin{array}{l}35 \\
50\end{array}$ & $\begin{array}{l}64 \\
78\end{array}$ \\
\hline Wh-Ah & $\begin{array}{l}\text { HA-A } \\
\text { HA-B }\end{array}$ & $\begin{array}{l}54.4 \\
51.8\end{array}$ & $\begin{array}{l}4.01 \\
5.83\end{array}$ & $\begin{array}{l}4.22 \\
4.97\end{array}$ & $\begin{array}{l}1.14 \\
0.74\end{array}$ & $\begin{array}{l}12.9 \\
10.4\end{array}$ & $\begin{array}{l}32 \\
48\end{array}$ & $\begin{array}{l}60 \\
79\end{array}$ \\
\hline Wh-Aeh & $\begin{array}{l}\text { HA-A } \\
\text { HA-B }\end{array}$ & $\begin{array}{l}53.5 \\
50.6\end{array}$ & $\begin{array}{l}3.48 \\
5.36\end{array}$ & $\begin{array}{l}3.57 \\
5.01\end{array}$ & $\begin{array}{l}1.29 \\
0.79\end{array}$ & $\begin{array}{l}15.0 \\
10.1\end{array}$ & $\begin{array}{l}29 \\
50\end{array}$ & $\begin{array}{l}60 \\
84\end{array}$ \\
\hline Wv & $\begin{array}{l}\text { HA-A } \\
\text { HA-B }\end{array}$ & $\begin{array}{l}54.5 \\
53.3\end{array}$ & $\begin{array}{l}4.22 \\
5.30\end{array}$ & $\begin{array}{l}4.71 \\
4.68\end{array}$ & $\begin{array}{l}1.08 \\
0.85\end{array}$ & $\begin{array}{l}11.6 \\
10.0\end{array}$ & $\begin{array}{l}33 \\
45\end{array}$ & $\begin{array}{l}54 \\
73\end{array}$ \\
\hline R5 & $\begin{array}{l}\text { HA-A } \\
\text { HA-B }\end{array}$ & $\begin{array}{l}55.2 \\
53.3\end{array}$ & $\begin{array}{l}3.85 \\
5.28\end{array}$ & $\begin{array}{l}5.49 \\
6.14\end{array}$ & $\begin{array}{l}1.21 \\
0.85\end{array}$ & $\begin{array}{c}10.1 \\
8.7\end{array}$ & $\begin{array}{l}32 \\
38\end{array}$ & $\begin{array}{l}48 \\
58\end{array}$ \\
\hline Whg & $\begin{array}{l}\text { HA-A } \\
\text { HA-B }\end{array}$ & $\begin{array}{l}53.9 \\
51.7\end{array}$ & $\begin{array}{l}4.75 \\
5.93\end{array}$ & $\begin{array}{l}4.81 \\
5.46\end{array}$ & $\begin{array}{l}0.95 \\
0.74\end{array}$ & $\begin{array}{r}11.2 \\
9.5\end{array}$ & $\begin{array}{l}35 \\
45\end{array}$ & $\begin{array}{l}67 \\
78\end{array}$ \\
\hline
\end{tabular}

t̀ Not determined. 


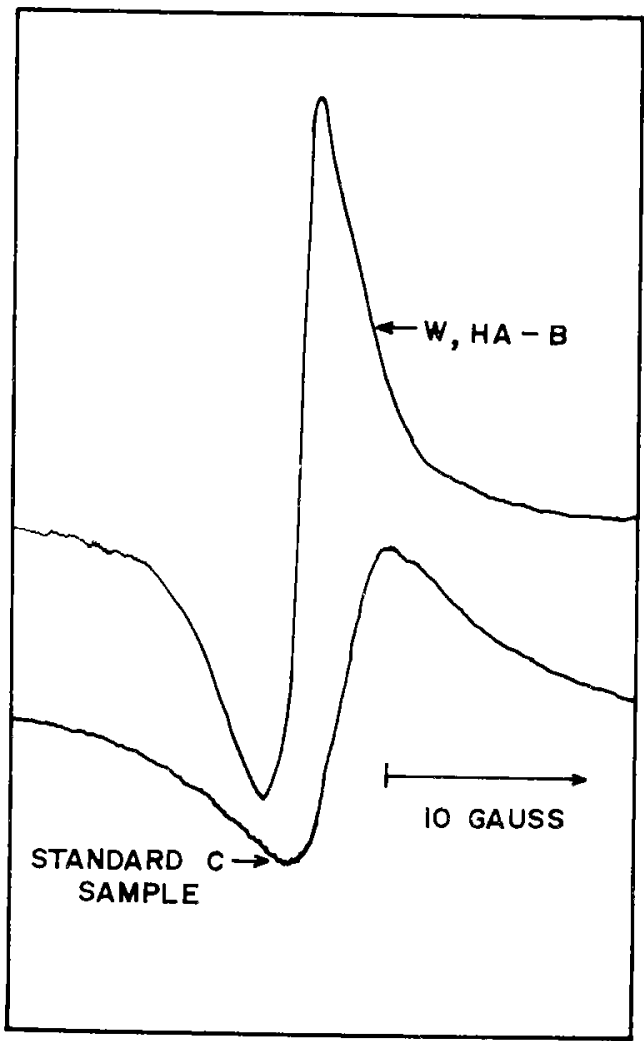

Fig. 1. The ESR spectrum of the Dark Brown (W), HA-B fraction. $g$-value, and b) as the line-width increased, the line-shape changed from asymmetric to Lorentzian to Gaussian. In particular, the line-shapes of the spectra of the humic acids obtained from the R5 soil were approximately Gaussian. A check was made to ensure that the asymmetry of the narrowest lines was not an instrumental artifact. The asymmetry of some of the spectra (Fig. 1 and Table 4) could be due to the presence of more than one kind of radical center; this is also suggested by the differences in lineshape of the spectra of different humic acid samples. The free radical content of the HA-A ranged from $3.0 \times 10^{11}$ to $10.7 \times$ $10^{17}$ spins/g and of the HA-B from $2.6 \times$ $10^{i \tau}$ to $14.9 \times 10^{i t}$ spins $/ g$. The standard deviation for several estimations of the radical content of given humic acids was approximately $\pm 3 \%$. Because of the uncertainty in the number of spins in the standard sample and because of differences in lineshape between the samples and standard, the accuracy of the results in terms of absolute spin concentration is unlikely to be better than $\pm 15 \%$. Spin concentrations were least for the $\mathrm{Hr}$, moderate for the Black $\mathrm{Ox}-1$ and Ox-2 and greatest for the R5 Ah horizon.

The spin concentration of the HA-A was significantly correlated $(95 \%$ level or greater) with the $\mathrm{C}: \mathrm{H}$ ratio $(r=0.86)$, the

Table 4. The free radical concentrations and ESR spectral characteristics of the HA-A and selected HA-B fractions

\begin{tabular}{|c|c|c|c|c|c|}
\hline Soil & Frac. & $\begin{array}{l}\text { Spins } g^{-1} \times \\
10^{17}\end{array}$ & $\begin{array}{c}g \\
\text { values }\end{array}$ & $\begin{array}{c}\text { Line-width } \\
\text { (peak to peak) } \\
\text { gauss }\end{array}$ & Line-shape \\
\hline $\mathrm{Hr}$ & HA-A & 3.0 & 2.0031 & 4.3 & $\begin{array}{l}\text { Slightly asymmetric } \\
(\simeq \text { Lorentzian })\end{array}$ \\
\hline \multirow[t]{2}{*}{ W } & HA-A & 5.2 & 2.0030 & 4.1 & $\begin{array}{l}\text { Slightly asymmetric } \\
(\simeq \text { Lorentzian })\end{array}$ \\
\hline & HA-B & 2.6 & 2.0028 & 2.9 & Lorentzian \\
\hline \multirow[t]{2}{*}{$O x-1$} & HA-A & 7.7 & 2.0030 & 4.1 & Lorentzian \\
\hline & HA-B & 4.0 & 2.0029 & 3.3 & Asymmetric \\
\hline$O x-2$ & $\mathrm{HA}-\mathrm{A}$ & 7.2 & 2.0030 & 4.1 & Lorentzian \\
\hline \multirow[t]{2}{*}{ Wh-Ah } & HA-A & 6.7 & 2.0031 & 4.4 & Lorentzian \\
\hline & HA-B & 9.0 & 2.0029 & 3.8 & Lorentzian \\
\hline Wh-Aeh & $\mathrm{HA}-\mathrm{A}$ & 9.0 & 2.0030 & 4.3 & Lorentzian \\
\hline Wv & HA-A & 6.6 & 2.0032 & 4.6 & Lorentzian-Gaussian \\
\hline \multirow[t]{2}{*}{ R5 } & HA-A & 10.7 & 2.0032 & 5.1 & $\simeq$ Gaussian \\
\hline & HA-B & 14.9 & 2.0032 & 5.3 & $\simeq$ Gaussian \\
\hline Whg & HA-A & 5.8 & 2.0032 & 4.9 & Lorentzian \\
\hline
\end{tabular}


extinction coefficient at $280 \mathrm{~nm}(r=0.95)$ and the proportion of hydrolyzable $N(r$ $=-0.85)$.

\section{UV and Visible Spectral Parameters}

Extinction coefficients at $280 \mathrm{~nm}\left(\mathrm{E}_{2 \times 0}\right)$ may be used as indices of the aromaticity of humic acids (Anderson et al. 1974). The $\mathrm{E}_{2 \mathrm{~s} 0}$ value of the HA-A was lowest for the Brown, $\mathrm{Hr}$ Ah horizon and generally increased along the sequence to a maximal value for the R5, Gray Luvisolic Ah horizon. The HA-B had lower $\mathrm{E}_{2 \rightarrow 0}$ values, but showed trends similar to the HA-A. The $E_{2, \infty}$ values of non-hydrolyzable residues were greater than those of the HA-A; those of the hydrolysates were much less.

The ratios of extinction coefficient at 465 $\mathrm{nm}$ to extinction coefficient at $665 \mathrm{~nm}\left(\mathrm{E}_{1}: \mathrm{E}_{\mathrm{t}}\right.$ ratios) of the HA-A were 4.9 for the $W v$ and R5 Ah horizons, somewhat less for the $\mathrm{Hr}$, and lowest for the $\mathrm{Ox}-1$ and $\mathrm{Ox}-2$ (Black), and W (Dark Brown) Ah horizons. The $E_{1}: E_{6}$ ratios of the $H A-B$ were in the range 3.2-3.8 except for the Wv soil, considerably less than the ratios of the HA-A.

As compared to the adjacent well drained Wh-Ah horizon, the Whg Ah had lower $\mathrm{E}_{250}$ values for the HA-A, the non-hydrolyzable HA-A and the HA-B (Table 5).

\section{Similarity Analyses}

Figure 2 is a similarity matrix based on the properties of the humus of the Ah horizons (Based on the analysis described by J. H. Rayner, 1966, in J. Soil Sci. 17: 79-92). In considering the first column, one notes a

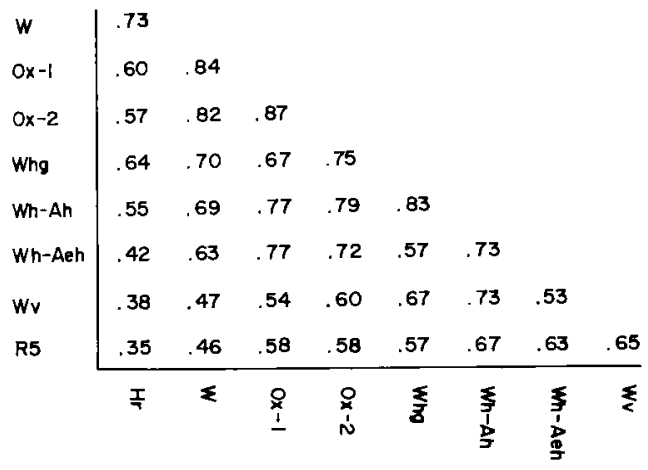

Fig. 2. Matrix of similarity coefficients (based on 22 humus characteristics) comparing pairs of Ah horizons.

progressive decrease in the level of similarity (similarity coefficient) between the $\mathrm{Hr} \mathrm{Ah}$ and the other $A h$ horizons in the sequence W, Ox-1, Ox-2, Wh-Ah, Wh-Aeh, WV and R5; that is, in accordance with decrease in similarity of morphological, chemical and environmental properties. Conversely, the reverse sequence is observed if one compares the other end of the spectrum, R5, with all other Ah horizons.

Figure 3 is a two-dimensional representation of the association of the most similar pairs and groups. The figure is drawn within the restrictions that the most similar pairs are adjacent and connected by a line of appropriate density and that the distance between individuals equals, as closely as possible in two dimensions, one minus the similarity coefficient. The $\mathrm{W}, \mathrm{Ox}-1$ and

Table 5. UV and visible spectral parameters of the HA-A and HA-B fractions

\begin{tabular}{|c|c|c|c|c|c|c|}
\hline \multirow[b]{2}{*}{ Soil } & \multicolumn{4}{|c|}{ HA-A } & \multicolumn{2}{|c|}{ HA-B } \\
\hline & $\mathrm{E}_{\mathbf{2 8 0}}$ & $\mathrm{E}_{\mathbf{2 8 0}}-\mathrm{NH} \dagger$ & $\mathrm{E}_{280}-\mathrm{H} \ddagger$ & $\mathrm{E}_{4}: \mathrm{E}_{6}$ & $\mathrm{E}_{280}$ & $\mathrm{E}_{4}: \mathrm{E}_{6}$ \\
\hline $\mathrm{Hr}_{\mathrm{r}}$ & 0.86 & 1.06 & 0.21 & 4.6 & .40 & 3.7 \\
\hline W & 1.09 & 1.36 & n.d. & 4.1 & .52 & 3.5 \\
\hline$O x-1$ & 1.20 & 1.51 & 0.19 & 4.3 & .60 & 3.3 \\
\hline$O x-2$ & 1.18 & 1.52 & n.d. & 4.3 & .63 & 3.5 \\
\hline Wh-Ah & 1.15 & 1.55 & 0.25 & 4.3 & .70 & 3.8 \\
\hline Wh-Aeh & 1.32 & 1.61 & 0.24 & 3.9 & .77 & 3.2 \\
\hline Wv & 1.22 & 1.54 & 0.22 & 4.9 & .81 & 4.6 \\
\hline R5 & 1.37 & 1.57 & 0.18 & 4.9 & .92 & 3.4 \\
\hline Whg & 1.04 & 1.18 & n.d. & 4.5 & .65 & 3.2 \\
\hline
\end{tabular}

†NH, non-hydrolyzable humic acids. $\ddagger \mathrm{H}$, humic acid hydrolysate. 


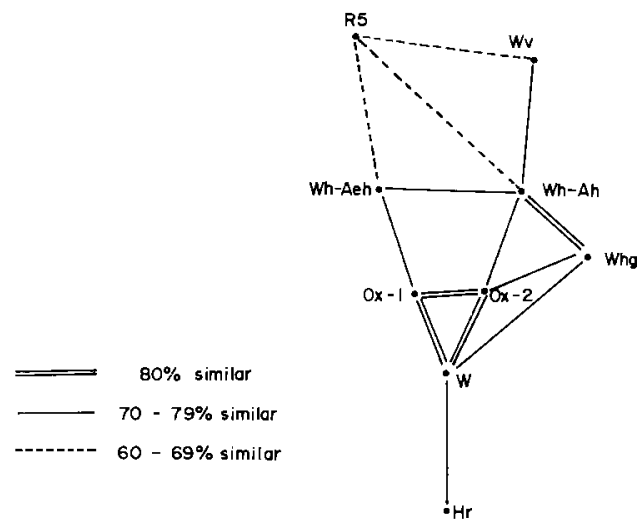

Fig. 3. Two-dimensional representation of the most similar pairs and groups of $A$ horizons, based on the similarity analysis of 22 humus characteristics.

$\mathrm{Ox}-2$, from relatively similar grassland environments, form a group with a high level of internal similarity. The $\mathrm{Hr}$ Ah is most similar to the W. The Wh-Ah and Wh-Aeh are similar to each other and transitional between the $O x-1$ and $O x-2$, and the Gray Luvisolic R5 and Wv. The Whg Ah, the one poorly drained soil, does not fit in well. Schematically, the depiction of the soils in Fig. 3 is similar to the distribution of the soil zones in Saskatchewan.

\section{DISCUSSION}

The results of this study suggest that the proportion of aromatic components or the degree of aromatic condensation of the humic acids increases in going from the Brown to the Gray Luvisolic zones. Evidence for this postulate includes the general increases in $\mathrm{C}: \mathrm{H}$ ratios, $\mathrm{E}_{240}$ values, resistance to acid hydrolysis and free radical concentrations of the HA-A and HA-B, in the Brown to Gray Luvisolic sequence. The strong correlations between $\mathrm{C}: \mathrm{H}$ ratio and free radical content, and $E_{2,0}$ and free radical content are similar to those reported by Riffaldi and Schnitzer (1972a), who used their results as evidence that free radical concentration could be correlated with increases in the degree of aromatic condensation of humic acids.

Over the range of soils studied, differences in the HA-B fraction were similar to those observed for the HA-A, and similar conclusions could result from considering either fraction. This indicates that the HA-B is an actual humus fraction, not an artifact of the extraction-fractionation method. In an earlier paper it was postulated that the HA-B was clay-adsorbed humus (Anderson et al. 1974).

The organic fraction of the Brown $\mathrm{Hr} \mathrm{Ah}$ horizon has a large proportion of humin (nonextractable organic constituents), particularly partially decomposed roots, relatively large amounts of clay-associated humus (HA-B) and a ratio of HA-A to FA-A of 0.8. As compared to the other A horizons studied, the HA-A has a low $\mathrm{E}_{2 \mathrm{~s} 0}$ value, narrow $\mathrm{C}: \mathrm{H}$ ratio, a high degree of hydrolyzability in acid, and a low free radical content.

The $E_{2 s 0}$ values of the non-hydrolyzable residues and hydrolysates of the $\mathrm{HA}-\mathrm{A}$ indicate a concentration of the strongly absorbing structures in the non-hydrolyzable fraction (Cheshire et al. 1967; Riffaldi and Schnitzer 1972b). The $\mathrm{E}_{2 \times n}$ value of the $\mathbf{H r}$ HA-A, the lowest observed, suggests that the aromatic components are less condensed than in the Black and Gray soils. The low free radical content of the HA-A is consistent with other properties, suggesting low levels of aromatic condensation (Riffaldi and Schnitzer 1972a). The HA-A of the Hr corresponds to the young or weakly humified forms described by Kononova and Alexandrova (1973). Volkovintser (1969), who reported similar characteristics for Chestnut soils in Siberia, described the humic acids as immature, and the relatively large fulvic acid component as humic acid precursors. He postulated a low degree or rate of humification, a consequence of the reduced biological activity due to the cold, arid climate.

The nature of the humus of the Dark Brown W Ah horizon is transitional between the Brown and Black Ah horizons.

The Black Ox-1 and Ox-2 Ah horizons have relatively large amounts of humus and substantial proportions of both HA-A and $\mathrm{HA}-\mathrm{B}$. The $\mathrm{C}: \mathrm{H}$ ratios, free radical contents and $\mathrm{E}_{\mathrm{gro}}$ of the non-hydrolyzable HA-A indicate that the aromatic components of the humic acids of these Ah horizons are more strongly condensed than those of the $\mathrm{Hr} \mathrm{Ah}$ 
horizon. There are substantial proportions of hydrolyzable material, particularly $\mathrm{N}$. This fraction is the most active portion of the organic matter from a turnover standpoint (Campbell et al. 1967) and, together with the potentially labile, clay-associated HA-B, probably accounts for the high nutrient supplying power of Black Chernozemic soils. Generally, the characteristics of the humus suggest favorable conditions for humus formation and the transformation of the initial immature forms to relatively aromatic, stable forms. It is postulated that such properties are the product of longer periods of, and more intense, biological activity, a consequence of the more moist soil environment as compared to the Brown soil.

The Wh-Ah and Wh-Aeh Dark Gray soils may be considered transitional between the Black and Gray soils studied.

The Ah horizons of the forested Gray Luvisolic soils, R5 and Wv, are thin, a consequence of the surface additions of most plant residues and the absence of soil-mixing fauna (personal observations). The $W v$ and R5 Ah horizons have relatively large HA-A fractions in comparison to the HA-B. The wide $C: H$ ratios, high free radical contents, and the high $E_{2 n 0}$ values of both the HA-A and its non-hydrolyzable fraction suggest a strongly aromatic HA-A. The levels of $\mathrm{C}$ and $\mathrm{N}$ hydrolyzability are the lowest of the soils studied. The high $\mathrm{E}_{0 \times(x)}$ values and free radical contents, and lower levels of $\mathrm{C}$ and $\mathrm{N}$ hydrolyzability suggest that the HA-B is more strongly aromatic than that encountered in grassland Ah horizons. Radiocarbon dates and tracer studies have demonstrated that humus formation and degradation is rapid in Gray Luvisolic soils (Campbell et al. 1967; Shields and Paul 1973). In this study we have data indicating a mature, aromatic humic acid component. The high $E_{1}: E_{0}$ ratios of the HA-A fractions of the WV and R5 suggest that they are of relatively low molecular weight (Anderson et al. 1974). Swift et al. (1970) postulate an increase in aromaticity and decrease in molecular weight with advancing humification. The products of the oxidative degradation of the humic acid, the fulvic acids, were not studied. The lower horizons of Gray Luvi- solic soils contain large amounts of fulvic acids (Anderson 1972), many of which may have been translocated from the Ah horizon.

The low $\mathrm{C}: \mathrm{H}$ ratio and $\mathrm{E}_{2 \times 0}$ values for the HA-A of the Why Ah horizon indicate a lesser degree of aromatic condensation than that encountered in the adjacent, well drained Wh soil. The primitive nature of the humus of the Whg horizon can be ascribed to unfavorable conditions for humification due to the excess wetness in this poorly drained soil.

In summary, the general increases in the proportion and condensation of aromatic components in the humic acids indicate that the intensity or degree of humification processes in well drained soils increases in going from the arid Brown to the more humid Gray Luvisolic soil zone.

\section{ACKNOWLEDGMENT}

The technical assistance of Mr. Lorne F. Weeks is gratefully acknowledged.

ANDERSON, D. W. 1972. The characteristics of organic matter of grassland, transitional and forest soils. Ph.D. Thesis, University of Saskatchewan, Saskatoon. Univ. Microfilms, Ann Arbor, Mich. (Diss. Abstr. 72-31368).

ANDERSON, D. W., PAUL, E. A. and ST. ARNAUD, R. J. 1974. Extraction and characterization of humus with reference to clayassociated humus. Can. J. Soil Sci. 54: 317-323. BAIER, W. and RUSSELO, D. A. 1970. Soil temperature and soil moisture regimes in Canada. Proc. 8th meeting of Canada Soil Survey Committee, Ottawa. pp. 35-65.

BREMNER, J. M. 1965. Total nitrogen. In C. A. Black, ed. Methods of soil analysis. Part 2 . Agronomy 9: 1149-1178. Amer. Soc. Agron., Madison, Wisc.

CAMPBEll, C. A., PAUL, E. A., RENNIE, D. A. and McCALLUM, K. J. 1967. Applicability of the carbon-dating method of analysis to soil humus studies. Soil Sci. 104: 217-224. CHESHIRE, M. V., CRANWELL, P. A., FALSHAW, C. P., FLOYD, A. J. and HAWORTH, R. D. 1967. Humic acid - If. Structure of humic acids. Tetrahedron 23: 1669-1682.

IVANOVA, E. N., LETUNOV, P. A., ROSOV, N. N. and FRIDLAND, V. M. 1962. Soil-geographical zoning of the U.S.S.R. Israel Program for Scientific Translocations, Jerusalem.

KONONOVA, M. M. and ALEXANDROVA, I. V. 1973. Formation of humic acids during plant residue humification and their nature. Geoderma 9: 157-164. 
MEBIUS, L. J. 1960. A rapid method for the determination of organic carbon in soils. Anal. Chim. Acta 22: 120-125.

MITCHELL, J., MOSS, H. C. and CLAYTON, J. S. 1944. Soil Survey of Southern Saskatchewan, Rep. No. 12. Univ. of Saskatchewan, Saskatoon, Sask.

NORRIS, J. M. 1970. Multivariate methods in the study of soils. Soils Fert. 33: 313-318.

RIFFALDI, R. and SCHNITZER, M. 1972a. Electron spin resonance spectrometry of humic substances. Soil Sci. Soc. Amer. Proc. 36: 301-305.

RIFFALDI, R. and SCHNITZER, M. $1972 b$. Effects of diverse experimental conditions on ESR spectra of humic substances. Geoderma 8: $1-10$.
SHIELDS, J. A. and PAUL, E. A. 1973. Decomposition of ${ }^{14} \mathrm{C}$-labelled plant material under field conditions. Can. J. Soil Sci. 53: 297-306.

ST. ARNAUD, R. J. and WHITESIDE, E. P. 1963. Morphology and genesis of a Chernozemic to Podzolic sequence of soil profiles in Saskatchewan. Can. J. Soil Sci. 44: 88-99.

SWIFT, R. S., THORNTON, B. K. and POSNER, A. M. 1970. Spectral characteristics of a humic acid fractionated with respect to molecular weight using an agar gel. Soil Sci. 110: 93-99.

VOLKOVINTSER, V. I. 1969. Soil formation in the steppe basins of Southern Siberia. Sov. Soil Sci. 4: 383-391. 